Check for updates

Cite this: RSC Adv., 2019, 9, 39037

Received 17th June 2019

Accepted 11th November 2019

DOI: $10.1039 / \mathrm{c} 9 \mathrm{ra0} 4531 \mathrm{~g}$

rsc.li/rsc-advances

\section{A novel synthetic strategy for hydroxyl-terminated polybutadiene containing high cis-1,4 contents based on a $\mathrm{Ni}($ II)-coordinated anionic initiating system $\dagger$}

\begin{abstract}
Xin Min iD
In this study, novel hydroxyl-terminated polybutadiene (HTPB) with a high cis-1,4 content was developed using a tert-butyl dimethyl siloxy dimethyl propyl lithium (Li)-naphthenate nickel (Ni)-boron trifluoride (B) initiating system ( $\mathrm{Li}-\mathrm{Ni}-\mathrm{B})$. The effects of the material ratio and the addition sequence on the cis-1,4 content and molecular weight of HTPB were studied, and the results were discussed. The optimal Li/Ni ratio was $10: 1$, and the optimal Li/B ratio was $1: 2$. HTPB prepared by the $\mathrm{Li}-\mathrm{Ni}-\mathrm{B}$ system was characterized by Fourier transform infrared spectroscopy (FTIR), ${ }^{1} \mathrm{H}$ nuclear magnetic resonance $\left({ }^{1} \mathrm{H}\right.$ NMR) spectroscopy, and ${ }^{13} \mathrm{C}$ nuclear magnetic resonance $\left({ }^{13} \mathrm{C}-\mathrm{NMR}\right)$ spectroscopy. The results suggested high cis-1,4 contents in HTPB synthesized using Li-Ni-B (cis-1,4 > 95\%). The comparison of the cis-1,4 contents in the HTPB samples obtained by anionic polymerization and the Li-Ni-B system revealed the advantages of the latter compared to the former
\end{abstract}

\section{Introduction}

Hydroxyl-terminated polybutadiene (HTPB) is an important liquid rubber with superior transparency and low viscosity. The excellent physical properties of НTPB make it a useful component in special coatings and functional adhesives and as a binder in solid rocket propellants. ${ }^{\mathbf{1 , 2}}$ HTPB is the main adhesive material used in solid rocket propellants. Due to the low temperature of the upper atmosphere, the adhesives in solid rocket propellants are easily embrittled, especially when the $T_{\mathrm{g}}$ or crystallinity of the adhesive material is high. Even slight embrittlement of the adhesive materials will result in terrible precision issues and affect the flight stability of the rocket. Hence, reducing the $T_{\mathrm{g}}$ and crystallinity of HTPB is very important for it to be used as a solid rocket propellant. This work presents an idea to solve the problem.

Based on steric configuration, the microstructure of HTPB can be divided into 1,4 and 1,2 unit structures, of which the 1,4 unit can again be divided into cis-1,4 and trans-1,4 units. Due to the low energy barrier for internal rotation, the glass transition temperature $\left(T_{\mathrm{g}}\right)$ of the segments with the cis-1,4 unit is much lower than that of the segments with the 1,2 unit $\left(T_{\mathrm{g} \text { cis }-1,4}=-106{ }^{\circ} \mathrm{C}, T_{\mathrm{g} 1,2}=-15^{\circ} \mathrm{C}\right)$. This means that the segments made of cis-1,4 units can maintain flexibility even

Department of Applied Chemistry, School of Nature and Applied Sciences, Northwestern Polytechnical University, Dongxiang Road 1, 710072, Xi'an, China. E-mail:15991672082@163.com

$\dagger$ Electronic supplementary information (ESI) available. See DOI: 10.1039/c9ra04531g at an extremely low temperature compared to those with the 1,2 unit structure. Moreover, the trans-1,4 unit can crystallize easily at low temperatures due to the aligned chain segment; therefore, its chain segment will be locked in the crystalline region at low temperatures. Hence, the contents of both the 1,2 and trans-1,4 units in HTPB can seriously affect its lowtemperature mechanical property and therefore, the content of the cis-1,4 unit is a very important technical parameter to judge and determine the final low-temperature flexibility of HTPB. ${ }^{3}$

Two synthesis methods using butadiene monomers are currently used to obtain HTPB: free radical polymerization ${ }^{\mathbf{4 - 6}}$ and anionic polymerization. ${ }^{7}$ The details of anionic polymerization to obtain $\mathrm{HTPB}$ have been reported so far. ${ }^{8}$ However, the content of cis-1,4 in HTPB obtained by anionic polymerization can only reach $30-40 \%$, which is still not satisfactory for standard applications. The low coordination ability of alkyl lithium is the reason behind the low cis-1,4 content. Coordination polymerization based especially on the $\mathrm{Ni}(\mathrm{II})$ complex has widely been employed for the synthesis of butadiene rubber with high cis-1,4 unit contents $(>95 \%) .{ }^{9-14}$ However, the existing catalytic systems cannot be directly used to prepare hydroxyl-terminated polybutadiene. Technically, hydroxyl groups do not exist in the Ni complexes or the structure of the alkylation reagent, indicating the inability to prepare polymers containing terminal hydroxyl groups.

A study (Eur. Polym. J., 1970, 6, 1359-1370) has reported the use of a system containing nickel isopropyl salicylate, boron trifluoride diethyl etherate and $n$-butyl lithium to synthesize 
high cis-1,4 content PB. However, this system cannot synthesize hydroxyl-terminated polybutadiene because there are no protected hydroxyls in the alkylating agent ( $n$-butyl lithium) to produce the terminal hydroxyl group after polymerization. Thus, we introduced protected hydroxyl groups in the structure of the alkylating agent to obtain a hydroxyl-terminated polymer.

In this work, a novel coordinated anionic initiating system was developed to prepare HTPB containing high cis-1,4 content. This coordinated anionic initiating system combines the advantages of anionic polymerization with those of coordination polymerization. During the process, alkyl lithium could easily be obtained by a hydroxyl-functionalized chemical construction to replace alkyl aluminum in the alkylate $\mathrm{Ni}$ (II) complex, and then, the hydroxyl groups could be introduced at the end of polybutadiene. Moreover, the coordination ability of the Ni(II) complex may yield high cis-1,4 content in polybutadiene. Overall, hydroxyl-terminated polybutadiene containing elevated cis-1,4 contents could be obtained through the proposed novel coordinated anionic initiating system. Our group has published a report on HTPB synthesis using a $\eta^{3}-\pi$ allyl acetoxyl Ni complex; however, it is not the same as this work. Firstly, the initiator using in the published work was $\left[\mathrm{Ni}\left(\eta^{3}-\mathrm{CH}_{2} \mathrm{CHCHCH}_{2} \mathrm{OOCCH}_{3}\right)\right]\left[\mathrm{BPh}_{4}{ }^{\mathrm{F}}\right]$, which is a single component initiator. In contrast, the initiating system used in this work is a $\mathrm{Li}-\mathrm{Ni}-\mathrm{B}$ three-component system, which is completely different from $\left[\mathrm{Ni}\left(\eta^{3}-\mathrm{CH}_{2} \mathrm{CHCHCH}_{2} \mathrm{OOCCH}_{3}\right)\right]$ $\left[\mathrm{BPh}_{4}{ }^{\mathrm{F}}\right]$.

Secondly, although $\left[\mathrm{Ni}\left(\eta^{3}-\mathrm{CH}_{2} \mathrm{CHCHCH}_{2} \mathrm{OOCCH}_{3}\right)\right]\left[\mathrm{BPh}_{4}{ }^{\mathrm{F}}\right]$ has advantages in theoretical research, the facility requirements, technical requirements and the cost of material are too high for industrialization. Thus, we have designed the cheaper and more convenient $\mathrm{Li}-\mathrm{Ni}-\mathrm{B}$ initiating system to suit industrialization.

\section{Experimental methods}

Butadiene (15\% wt in $n$-hexane), TCI; 3-chloro-2,2-dimethyl-1propanol (99\%), J\&K; imidazole (99\%), J\&K; lithium (99.5\%), Acros; tetrabutylammonium fluoride $\left(1 \mathrm{~mol} \mathrm{~L}^{-1}\right.$ in THF), TCI; nickel naphthenate (98\%), TCI; boron trifluoride diethyl etherate ( $\left.98 \%, \mathrm{BF}_{3} 46.5 \%\right)$, Aladdin; toluene, AR, Aladdin; $n$ hexane, AR, Aladdin; cyclohexane, AR, Aladdin; benzene, AR, Aladdin; tetrahydrofuran (THF), AR, Aladdin; $N, N$-dimethylformamide (DMF), AR, Aladdin; methanol, AR, Aladdin.

All the solvents used in the experiments were subjected to the following purification process: first, hydrogenated calcium was added in the solvents. Secondly, decompression distillation was performed, and fractions from specific temperatures were collected. Thirdly, a molecular sieve was added when the solvents were stored. Fourth, the solvents were purified with high purity argon to replace any traces of air.

Butadiene was passed through a desiccant system with soda lime after distillation and dissolution in the refined solvent. Then, an appropriate amount of TBDMSODPrLi was added to eliminate impurity. $n$-Butyl lithium was not appropriate because it is frequently formed single hydroxyl-terminated $\mathrm{PB}$, and the hydroxyl value of the pre-macromolecule was uncontrollable.

\section{Synthesis of tert-butyl dimethyl siloxy dimethyl propyl lithium (TBDMSODPrLi)}

Standard Schlenk techniques were utilized to control all the moisture- and air-sensitive compounds under a high-purity argon atmosphere. TBDMSODPrCl $11.8 \mathrm{~g}$ (0.05 mol) was dissolved in $50 \mathrm{~mL}$ cyclohexane under an argon atmosphere. $150 \mathrm{~mL}$ cyclohexane and $3.5 \mathrm{~g}$ lithium were added in a dry flask under the argon atmosphere, and the system was warmed to $50{ }^{\circ} \mathrm{C}$. During this time, the cyclohexane solution containing TBDMSODPrCl was added drop-wise under the argon atmosphere. The mixture was warmed to $70{ }^{\circ} \mathrm{C}$ and stirred for $6 \mathrm{~h}$. After the solution became turbid, the mixture was cooled down to room temperature. The mixture was concentrated under the argon atmosphere and filtered to remove the salt. The TBDMSODPrLi initiator product was kept in the cyclohexane solution under a sealed condition. Because the solution of the alkyl lithium-based initiator was sensitive to air and water, it needed to be preserved at a low temperature under an argon atmosphere as well. The solution of alkyl lithium was very sensitive to air and water, so they need to be preserved in low temperature under argon atmosphere.

\section{Synthesis of HTPB containing high cis- 1,4 content}

The experiments followed the Schlenk operation. Butadiene solution $10 \mathrm{~mL}(15 \%$ wt in $n$-hexane) was added in a Schlenk bottle. Then, TBDMSODPrLi $\left(0.5 \mathrm{~mol} \mathrm{~L}^{-1}\right.$ in cyclohexane), nickel naphthenate and boron trifluoride diethyl etherate were added in a certain sequence under an argon atmosphere and stirred for $4 \mathrm{~h}$ at $50{ }^{\circ} \mathrm{C}$ temperature. After several hours, $0.2 \mathrm{~mL}$ epoxy ethane was added and stirred for $1 \mathrm{~h}$, and then, $0.5 \mathrm{~mL}$ of methanol was added to terminate the reaction. The solvent was removed under vacuum. The polymer was dissolved in THF and washed with $300 \mathrm{~mL}$ methanol for 3 times. A colorless and transparent viscous liquid was obtained.

Dry HTPB $1 \mathrm{~g}$ was dissolved in $10 \mathrm{~mL}$ tetrahydrofuran, and then, tetrabutylammonium fluoride $1 \mathrm{~mL}$ was added and stirred at $50{ }^{\circ} \mathrm{C}$ for $4 \mathrm{~h}$. The solvent was removed under vacuum. The HTPB sample was dissolved in THF and washed with $300 \mathrm{~mL}$ methanol for 3 times. A colorless and transparent viscous liquid was obtained.

\section{Analytical methods}

A Nicolet iS10 Fourier transform infrared spectrometer (Thermo Fisher Scientific) was used for the infrared spectroscopy of the polymer. The molecular weight and molecular weight distribution of the polymers were measured by gel permeation chromatography (GPC) using a DAWN EOS type gel osmotic chromatography column with multi-angle laser light scattering (SEC-MALLS). The model of the light scattering detector was Wyatt DAWN HELEOS II, which is an eighteen-angle laser light scattering detector with $d_{\mathrm{n}} / d_{\mathrm{c}}=0.12$, which can test the absolute $M_{\mathrm{w}}$ of the polymer without a polystyrene standard calibration curve and calculate the $M_{\mathrm{n}}$ of the polymer by a series of 
standard methods. Bruker Avance-400 NMR was used to confirm the ${ }^{1} \mathrm{H}$ NMR and ${ }^{13} \mathrm{C}$ NMR spectra of the polymer.

(1) The FTIR test of HTPB: the $\mathrm{CH}_{2} \mathrm{Cl}_{2}$ solution of HTPB was coated on $\mathrm{KBr}$ tablets and the spectrum was recorded; scanning range: $500-4000 \mathrm{~cm}^{-1}$, resolution: $4 \mathrm{~cm}^{-1}$, and scanning times: 16 times.

(2) ${ }^{1} \mathrm{H}-\mathrm{NMR}$ and ${ }^{13} \mathrm{C}-\mathrm{NMR}$ analysis: testing temperature $25{ }^{\circ} \mathrm{C} ; \mathrm{CDCl}_{3}$ as the solvent; internal standard: tetramethylsilane (TMS).

(3) The evaluation of molecular weight of the polymer, molecular weight distribution and the $d_{\mathrm{n}} / d_{\mathrm{c}}$ value: chromatographic column model- 5 microns 500 ÅMZ-Gel SD plus $103 \AA$ $(300 \times 8.0 \mathrm{~mm})$, mobile phase - chromatographic grade THF, flow rate $-0.5 \mathrm{~mL} \mathrm{~min}{ }^{-1}$, test temperature $-25{ }^{\circ} \mathrm{C}$, concentration of sample solution $-10 \mathrm{mg} \mathrm{mL} \mathrm{m}^{-1}$, sample amount $-200 \mu \mathrm{L}$.

(4) The content of the 1,4 structure and the 1,2 structure in the microstructure of HTPB was tested by ${ }^{1} \mathrm{H}-\mathrm{NMR}$ and calculated according to formula (1). The test results were verified by FTIR using formula (2).

$$
\mathrm{B} \%=\left(1-\frac{2 I_{(5.01-4.8)}}{2 I_{(5.38)}+I_{(5.01-4.8)}}\right) \times 100 \%
$$

$I=$ the integral area of certain ${ }^{1} \mathrm{H}-\mathrm{NMR}$ peaks of HTPB; $\mathrm{B} \%=$ the content of 1,4 structure in HTPB

$$
\begin{gathered}
C_{\mathrm{c}} \%=\frac{\frac{D_{724 \mathrm{~cm}^{-1}}}{K_{\mathrm{c}}}}{\frac{D_{724 \mathrm{~cm}^{-1}}}{K_{\mathrm{c}}}+\frac{D_{911 \mathrm{~cm}^{-1}}}{K_{\mathrm{v}}}+\frac{D_{967 \mathrm{~cm}^{-1}}}{K_{\mathrm{t}}}} \times 100 \% \\
C_{\mathrm{v}} \%=\frac{\frac{D_{911 \mathrm{~cm}^{-1}}}{K_{\mathrm{v}}}}{\frac{D_{724 \mathrm{~cm}^{-1}}}{K_{\mathrm{c}}}+\frac{D_{911 \mathrm{~cm}^{-1}}}{K_{\mathrm{v}}}+\frac{D_{967 \mathrm{~cm}^{-1}}}{K_{\mathrm{t}}}} \times 100 \% \\
C_{\mathrm{t}} \%=\frac{\frac{D_{967 \mathrm{~cm}^{-1}}}{K_{\mathrm{t}}}}{\frac{D_{724 \mathrm{~cm}^{-1}}}{K_{\mathrm{c}}}+\frac{D_{911 \mathrm{~cm}^{-1}}}{K_{\mathrm{v}}}+\frac{D_{967 \mathrm{~cm}^{-1}}}{K_{\mathrm{t}}}} \times 100 \%
\end{gathered}
$$

$D=$ the absorbance of the corresponding position in the FTIR spectra; $K_{\mathrm{c}}=$ the absorption coefficient of the cis-1,4 structure in the $720-740 \mathrm{~cm}^{-1}$ window, and the value was $31.4 \mathrm{~mol}^{-1} \mathrm{~cm}^{-1}$; $K_{\mathrm{v}}=$ the absorption coefficient of the 1,2 structure at $911 \mathrm{~cm}^{-1}$, and the value was $151.0 \mathrm{~mol}^{-1} \mathrm{~cm}^{-1} ; K_{\mathrm{t}}=$ the absorption coefficient of the trans-1,4 structure at $967 \mathrm{~cm}^{-1}$, and the value was $117.0 \mathrm{~mol}^{-1} \mathrm{~cm}^{-1} ; C_{\mathrm{c}} \%, C_{\mathrm{v}} \%$, and $C_{\mathrm{t}} \%$ represent the content of the cis-1,4 structure, 1,2 structure, trans-1,4 structure, respectively.

(5) The concentration of TBDMSODPrLi was confirmed by the standards from the People's Republic of China non-ferrous metals industry YS/T 830-2012.

(6) The calculation method of the microstructure content via ${ }^{13} \mathrm{C}$-NMR was based on previous work. ${ }^{3}$

\section{Measuring method of hydroxyl value}

The specific experimental method used was as follows: phthalic anhydride ( $35 \mathrm{~g}$ ) was dissolved in $250 \mathrm{~mL}$ pyridine (called 'acetylated mixture solution'). After $24 \mathrm{~h}$, some samples were accurately weighed, and $8 \mathrm{~mL}$ acetylated mixed solution was added, refluxed at $115{ }^{\circ} \mathrm{C}$ for $1 \mathrm{~h}$, and then, $8 \mathrm{~mL}$ pyridine and $16 \mathrm{~mL}$ water were added from the top of the condensation tube and allowed to react for $15 \mathrm{~min}$. The titrations were performed using $\mathrm{KOH}$ solution $\left(0.5 \mathrm{~mol} \mathrm{~L}^{-1}\right.$ in water) and phenolphthalein as the indicator. Hydroxyl value $=\left(0.5\left(V_{1}-V_{2}\right) M_{\mathrm{n}}\right) / 1000 \mathrm{~m}$, where $V_{1}=$ titrant volume of blank sample, $V_{2}=$ titrant volume of experimental sample, $m=$ weight of experimental sample, $M_{\mathrm{n}}$ $=$ measured molecular weight by SEC.

\section{Result and discussion}

\section{Characterization of Li-Ni-B initiating system}

In view of the disadvantage that the Ni-Al-B system cannot synthesize НTРВ, hydroxyl-functionalized alkyl lithium was used to replace alkyl aluminium. A new alkylation mechanism for Li-Ni-B synthesis is described in Scheme 1. Ni(naph) $)_{2}$ was alkylated by TBDMSODPrLi, and the Ni(II) complex transformed into a $\mathrm{Ni}(\mathrm{I})$ or $\mathrm{Ni}(0)$ complex. In the alkylation process, the hydroxyl group was transferred from TBDMSODPrLi to the $\mathrm{Ni}$ complex, thus accomplishing the precondition of hydroxylfunctionalized polymers. Moreover, the strong electronwithdrawing ability of the boron trifluoride ether rendered the Ni complex (after the alkylation reaction) more likely to accept electrons from the butadiene monomer to form a coordination compound with the butadiene monomer and the nickel complex to yield the first reactive end. Then the insertion reaction occurred, where the butadiene monomer was inserted into the $\mathrm{Ni}-\mathrm{C}$ bond to yield a new active end. After continuous insertion of butadiene monomers, the molecular weight continuously increased, yielding a polymer with protected hydroxyls. At last, the reactive end group was terminated using ethylene oxide and methyl alcohol to form another hydroxyl end. At the end of hydrolysis reaction, dihydroxyl-terminated polybutadiene containing high cis-1,4 content was obtained.

When this TBDMSODPrLi initiating system was used as one of the three components, it seemed that the polymerization behavior would be similar to anionic polymerization. However, the $M_{\mathrm{n}}$ of HTPB was not relevant to the molar ratio between TBDMSODPrLi and the monomer, but was relevant to the molar ratio between $\mathrm{Ni}(\text { naph })_{2}$ and the monomer.

For example, the data in Table 2 (which is discussed detailed below) shows that $M_{\mathrm{n}}=58569 \mathrm{~g} \mathrm{~mol}^{-1}$ when $\mathrm{Li} / \mathrm{B}=1: 4$. The polymerization condition was $\mathrm{Ni}(\mathrm{naph})_{2}=2 \times 10^{-5} \mathrm{~mol}$, butadiene $(\mathrm{Bd})\left(10 \mathrm{~mL}\right.$ aq, $\left.18.5 \times 10^{-3} \mathrm{~mol}\right), \mathrm{Li} / \mathrm{Ni}=10: 1$, and the molar amount of $\mathrm{Li}$ was $2 \times 10^{-4} \mathrm{~mol}$; hence, $\mathrm{Bd} / \mathrm{Li}=18.5 \times$ $10^{-3} / 2 \times 10^{-4}=92.5$ and $\mathrm{Bd} / \mathrm{Ni}=925$. If the polymerization behavior was similar to that of anionic polymerization, the $M_{\mathrm{n}}$ of HTPB would have been $92.5 \times 54=4995 \mathrm{~g} \mathrm{~mol}^{-1}$, which does not match with the measured value. However, $\mathrm{Bd} / \mathrm{Ni}=925$ for HTPB with $M_{\mathrm{n}}=49950 \mathrm{~g} \mathrm{~mol}^{-1}$ is more suitable than $4995 \mathrm{~g}$ $\mathrm{mol}^{-1}$. Moreover, the cis-1,4 content in the synthesized HTPB did not reach $95 \%$ due to the weak coordination ability of lithium. Thus, the polymerization mechanism may not be typical of anionic polymerization. It is more likely to be coordination polymerization, and hence, this work does not discuss the main benefits of anionic polymerization. 

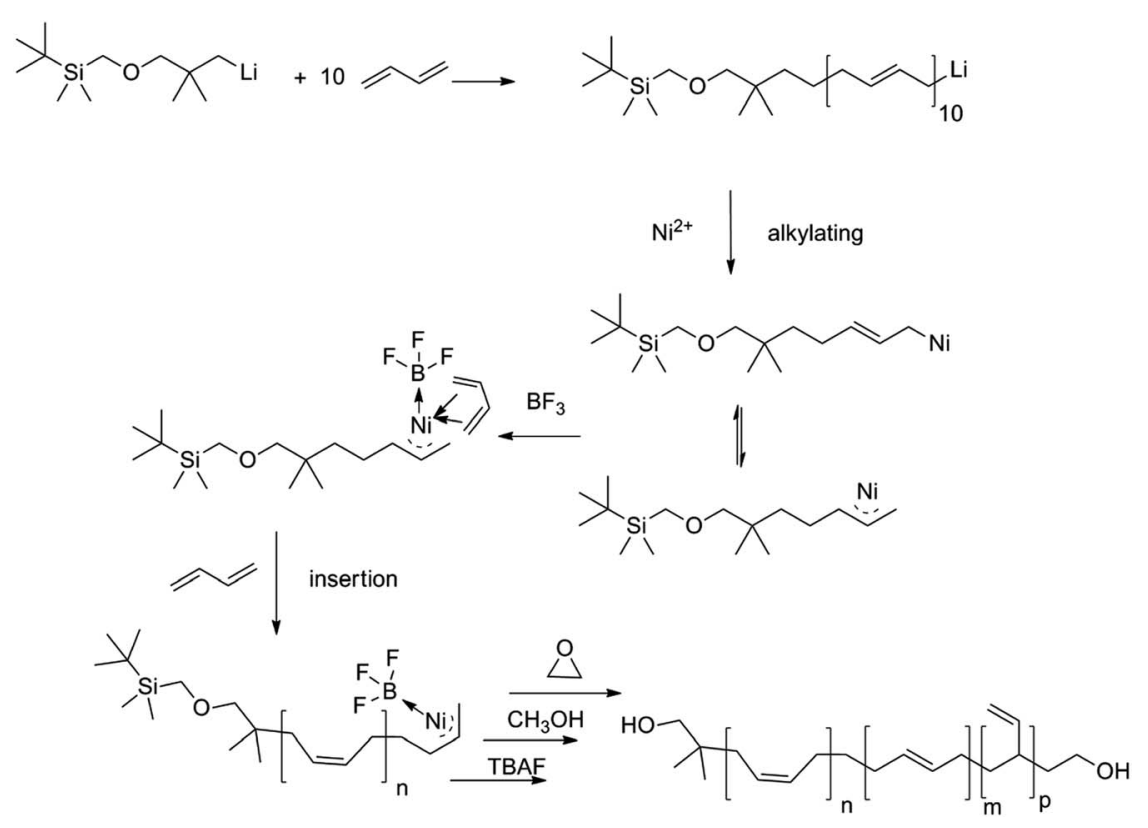

Scheme 1 The mechanism of the designed $\mathrm{Li}-\mathrm{Ni}-\mathrm{B}$ initiating system.

Table 1 The effect of addition sequence to $\mathrm{Li}-\mathrm{Ni}-\mathrm{B}$ catalytic system ${ }^{a}$

\begin{tabular}{lll}
\hline Addition sequence & $\begin{array}{l}\text { cis-1,4 } \\
\text { content }\end{array}$ & Conversion \\
\hline$(\mathrm{Li}+\mathrm{B})+\mathrm{Ni}^{b}$ & - & Trace \\
$(\mathrm{Li}+\mathrm{Ni})+\mathrm{B}^{c}$ & $95 \%$ & $85 \%$ \\
$\mathrm{Li}+\mathrm{Ni}+\mathrm{B}^{d}$ & $95 \%$ & $76 \%$ \\
$(\mathrm{Ni}+\mathrm{B})+\mathrm{Li}^{e}$ & $94 \%$ & $83 \%$ \\
$((\mathrm{Li}+\mathrm{Bd})+\mathrm{Ni})+\mathrm{B}^{f}$ & $97 \%$ & $98 \%$
\end{tabular}

${ }^{a}$ Polymerization conditions: Ni amount $2 \times 10^{-5} \mathrm{~mol}$, Bd (15 wt $\%, n-$ hexane) $10 \mathrm{~mL}, \mathrm{Li} / \mathrm{Ni}=10: 1, \mathrm{Li} / \mathrm{B}=1: 1,50{ }^{\circ} \mathrm{C}, 4 \mathrm{~h} .{ }^{b}$ Reaction of $\mathrm{Li}$ with $\mathrm{B}$ for $15 \mathrm{~min}$ at $50{ }^{\circ} \mathrm{C}$ followed by the addition of $\mathrm{Ni}$ under constant stirring for 15 min. ${ }^{c}$ Reaction of $\mathrm{Li}$ and $\mathrm{Ni}$ for $15 \mathrm{~min}$ at $50{ }^{\circ} \mathrm{C}$, and then $\mathrm{B}$ was added under stirring for $15 \mathrm{~min} .{ }^{d}$ Reaction of $\mathrm{Li}, \mathrm{Ni}$ and $\mathrm{B}$ for $15 \mathrm{~min}$ at $50{ }^{\circ} \mathrm{C}$. ${ }^{e}$ Reaction of $\mathrm{Ni}$ and $\mathrm{B}$ for $15 \mathrm{~min}$ at $50{ }^{\circ} \mathrm{C}$, followed by addition of Li under stirring for $15 \mathrm{~min} .{ }^{f}$ Reaction of $\mathrm{Li}$ and butadiene at a $\mathrm{Li} /$ butadiene molar ratio of $1: 10$ for $15 \mathrm{~min}$ at $50{ }^{\circ} \mathrm{C}$ followed by addition of $\mathrm{Ni}$ for $15 \mathrm{~min}$ and then $\mathrm{B}$ for $15 \mathrm{~min}$.

Table 2 The effect of Li/B to polymer properties ${ }^{a}$

\begin{tabular}{|c|c|c|c|c|c|}
\hline $\mathrm{Li} / \mathrm{B}$ & Conversion & $M_{\mathrm{n}}\left(\mathrm{g} \mathrm{mol}^{-1}\right)$ & $M_{\mathrm{w}} / M_{\mathrm{n}}$ & $\begin{array}{l}\text { Hydroxyl value } \\
\left(\mathrm{mmol} \mathrm{g}^{-1}\right)\end{array}$ & cis- 1,4 \\
\hline $5: 2$ & $35 \%$ & 94810 & 1.7 & 0.0207 & $84 \%$ \\
\hline $1: 2$ & $95 \%$ & 78010 & 1.3 & 0.0224 & $96 \%$ \\
\hline $1: 3$ & $93 \%$ & 64140 & 1.5 & 0.0281 & $96 \%$ \\
\hline $1: 4$ & $98 \%$ & 58569 & 1.9 & 0.0273 & $96 \%$ \\
\hline $1: 8$ & $98 \%$ & 38540 & 2.4 & 0.0363 & $97 \%$ \\
\hline
\end{tabular}

${ }^{a}$ Polymerization condition: nickel naphthenate $2 \times 10^{-5} \mathrm{~mol}$, Bd (15 wt $\%, n$-hexane) $10 \mathrm{~mL}, \mathrm{Li} / \mathrm{Ni}=10: 1,50{ }^{\circ} \mathrm{C}, 4 \mathrm{~h}$.

\section{The study of material ratio and addition sequence}

According to the discussion on the initiating mechanism, the three added components and their addition sequence is important. To evaluate the best addition sequence for $\mathrm{Ni}$, TBDMSODPrLi (Li) and boron trifluoride diethyl ether (B), different addition sequences were attempted, and the results are summarized in Table 1.

As per Table 1, the mixture of $\mathrm{Li}$ and B yielded large amounts of precipitate. Black Ni colloids were easily generated upon mixing the three materials, while the conversion was not very high. The combination between $\mathrm{Li}$ and $\mathrm{Ni}$ for $15 \mathrm{~min}$ followed by the addition of $\mathrm{B}$ reduced the formation of $\mathrm{Ni}$ colloids and yielded a higher conversion rate. After repeated attempts, the reaction of $\mathrm{Li}$ with a small amount of Bd solution $(0.5 \mathrm{~mL})$ followed by the addition of $\mathrm{Ni}$ under continuous stirring for $15 \mathrm{~min}$ led to the formation of a red colored system. During polymerization, the solution gradually became cloudy, and the viscosity increased. Thus, the optimal addition sequence was identified as $((\mathrm{Li}+\mathrm{Bd})+\mathrm{Ni})+\mathrm{B}$.

The effects of $\mathrm{Li} / \mathrm{B}$ on the cis-1,4 content of HTPB and molecular weight are exhibited in Table 2 . The cis-1,4 content and conversion rate were low at $\mathrm{Li} / \mathrm{B}$ ratios below $1: 2$ since boron trifluoride diethyl ether did not only react with alkyl lithium but also involved in a reaction with alkyl nickel. Hence, sufficient amounts of B could significantly improve the polymerization process and orientation. The $-1,4$ content in HTPB gradually increased with the amount of $\mathrm{B}$ since boron trifluoride ether, acting as a Lewis acid, could enhance the electron-deficient properties of $\mathrm{Ni}$, thereby strengthening the two-site coordination ability of the Ni atoms to the butadiene monomer. However, the addition of excess boron trifluoride ether led to large amounts of precipitate, as well as more chain transfer and chain termination effects, which induced the lowering of hydroxyls in the individual polymer molecules. In addition, since the solubility of boron trifluoride ether in nonpolar solvents is low, the amount of added boron trifluoride 
Table 3 The effect of Li/Ni on the cis-1,4 content of HTPB and molecular weight distribution ${ }^{a}$

\begin{tabular}{|c|c|c|c|c|c|c|}
\hline $\mathrm{Li} / \mathrm{Ni}$ & Conversion & Measured $M_{\mathrm{n}}\left(\mathrm{g} \mathrm{mol}^{-1}\right)$ & $M_{\mathrm{w}} / M_{\mathrm{n}}$ & $\begin{array}{l}\text { Hydroxyl value } \\
\left(\mathrm{mmol} \mathrm{g}^{-1}\right)\end{array}$ & cis-1,4 & Calculated $M_{\mathrm{n}}\left(\mathrm{g} \mathrm{mol}^{-1}\right)$ \\
\hline $2.5: 1$ & $40 \%$ & 94100 & 1.2 & 0.0208 & $95 \%$ & 96061 \\
\hline $10: 1$ & $93 \%$ & 79204 & 1.7 & 0.0249 & $95 \%$ & 80482 \\
\hline $20: 1$ & $95 \%$ & 58450 & 1.9 & 0.0294 & $95 \%$ & 67980 \\
\hline$*$ & $100 \%$ & 53280 & 1.1 & 0.0370 & $43 \%$ & 54097 \\
\hline
\end{tabular}

${ }^{a}$ Polymerization condition: Ni amount: $2 \times 10^{-5}$ mol, Bd (15 wt $\%, n$-hexane) $10 \mathrm{~mL}, \mathrm{Li} / \mathrm{B}=1: 2.5,50{ }^{\circ} \mathrm{C}, 4 \mathrm{~h} .{ }^{*} \mathrm{Without} \mathrm{B}$ and $\mathrm{Ni}, \mathrm{Li}$ amount: $2 \times$ $10^{-5} \mathrm{~mol}, \mathrm{Bd}\left(15 \mathrm{wt} \%, n\right.$-hexane) $10 \mathrm{~mL}, 50{ }^{\circ} \mathrm{C}, 4 \mathrm{~h}$.

ether could not be too much. Moreover, the PDI of the polymer was the lowest when $\mathrm{Li} / \mathrm{B}=1: 2$, which meant that the controllability of the polymerization process was better. Hence, the optimal $\mathrm{Li} / \mathrm{B}$ ratio was $1: 2$.

To verify the relationship between the experimental techniques and PDI, the butadiene monomer gas obtained from the supplier was refined by distillation and used for polymerization immediately. Similarly, oxirane (ethylene oxide) was also refined by distillation, and the experiments in Table 2 were repeated. This series of experimental results are shown in Table $\mathrm{S} 1$ (shown in ESI $\dagger$ ). The results in Table S1 $\uparrow$ are not significantly different from those in Table 2; PDI was slightly lower, which suggested the purity of the monomer and that oxirane is not the main reason for high PDI.

Thus, we speculated that the main reasons for high PDI could be:

(1) Li-Ni-B system has three components, which can produce more than one activity centre. The initiating activities of these activity centres are different, which may result in the different $M_{\mathrm{n}}$ values of the polymer.

(2) It can be observed that the PDI of HTPB was high when the amount of boron trifluoride diethyl etherate (B) was high, this because the addition of excess boron trifluoride ether led to large amounts of precipitate, as well as more chain transfer and chain termination effects, which induced the lowering og hydroxyls in the individual polymer molecules. A relatively narrow PDI (1.3, highlighted in Table 2) could be obtained by reducing the amount of boron trifluoride diethyl etherate.

(3) The alkyl lithium component TBDMSODPrLi was selfmade by the reaction of lithium and chlorohydrocarbons. Moreover, alkyl lithium cannot be used conventional purification methods due to its instability. Thus, it is hard to completely eliminate the unreacted chlorohydrocarbons and the suspending LiCl, which also can affect the PDI of HTPB.

Table 3 represents the influence of the $\mathrm{Li} / \mathrm{Ni}$ ratio on the cis1,4 content of HTPB and molecular weight distribution. The system revealed low cis-1,4 content during anionic polymerization without $\mathrm{Ni}$ and $\mathrm{B}$. The monomer conversion rate was not sufficiently high when $\mathrm{Li} / \mathrm{Ni}<10: 1$ since the Ni(II) complex could not properly alkylate at very low $\mathrm{Li}$ amounts. However, excess Li led to a wider molecular weight distribution due to an increased B amount compared with that of Li. Therefore, excess boron trifluoride ethyl ether would yield more chain transfer and chain termination effects but lower the number of hydroxyls.

Moreover, the conversion was relatively high when $\mathrm{Li} / \mathrm{Ni}=$ $10: 1$. Hence, the optimal Li/B ratio was $10: 1$. Although the conversion could be increased by $40 \%$ with a longer polymerization time at $\mathrm{Li} / \mathrm{Ni}=2.5: 1$, it was too long to satisfy the industrial demand. Hence, the optimal $\mathrm{Li} / \mathrm{Ni}$ ratio was determined as $10: 1$.

NMR was not enough to confirm the amount of -OH groups. Hence, we tested the hydroxyl values by chemical titration (the method is highlighted in the experimental section), and the results can be seen in Tables 2 and 3. To illuminate the problem, we chose the conditions in Table 3 as the examples. Hydroxyl value is the mole amount of $-\mathrm{OH}$ per gram of the molecule. Hence, assuming there are 2 moles of $-\mathrm{OH}$ in every chain, we obtained a series of calculated $M_{\mathrm{n}}$ values of HTPB by the formula $M_{\mathrm{n}}=2000 /$ hydroxyl value. If the calculated $M_{\mathrm{n}}$ is consistent with the measured $M_{\mathrm{n}}$, then the assumption is correct, else the assumption is wrong. We have listed the calculated values in Table 3 , which suggest that the calculated $M_{\mathrm{n}}$ is consistent with the measured $M_{\mathrm{n}}$, with the smallest

Table 4 Correlation between the monomer/initiator ratio and $M_{\mathrm{n}}{ }^{a}$

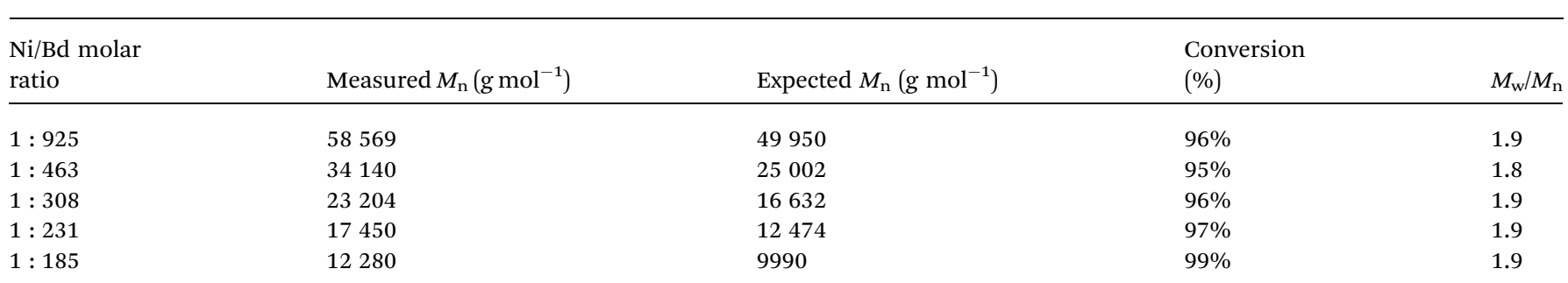

${ }^{a} \mathrm{Li} / \mathrm{Ni}=10: 1, \mathrm{Li} / \mathrm{B}=1: 4$ (molar ratio), polymerization temperature $=50{ }^{\circ} \mathrm{C}$, polymerization time $=4 \mathrm{~h}$. 


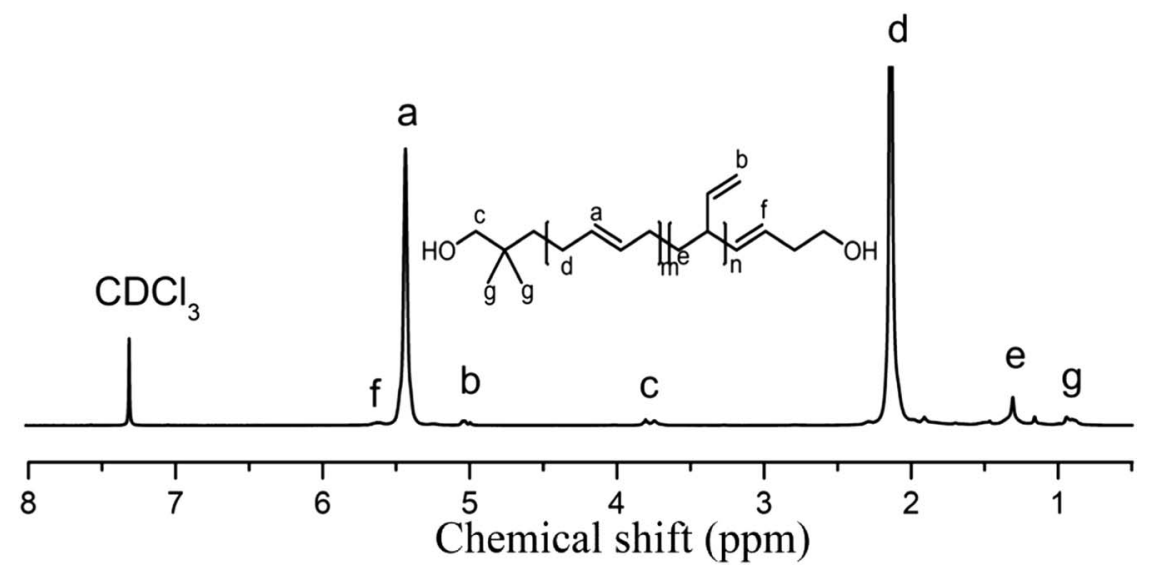

Fig. $1{ }^{1} \mathrm{H}-\mathrm{NMR}$ spectrum of HTPB synthesized by the $\mathrm{Li}-\mathrm{Ni}-\mathrm{B}$ initiator system.

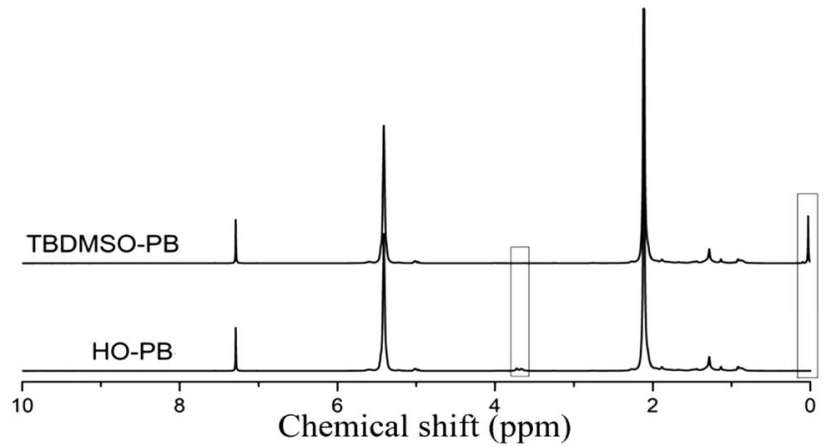

Fig. $2{ }^{1} \mathrm{H}-\mathrm{NMR}$ spectra of TBDMSO-PB and HO-PB.

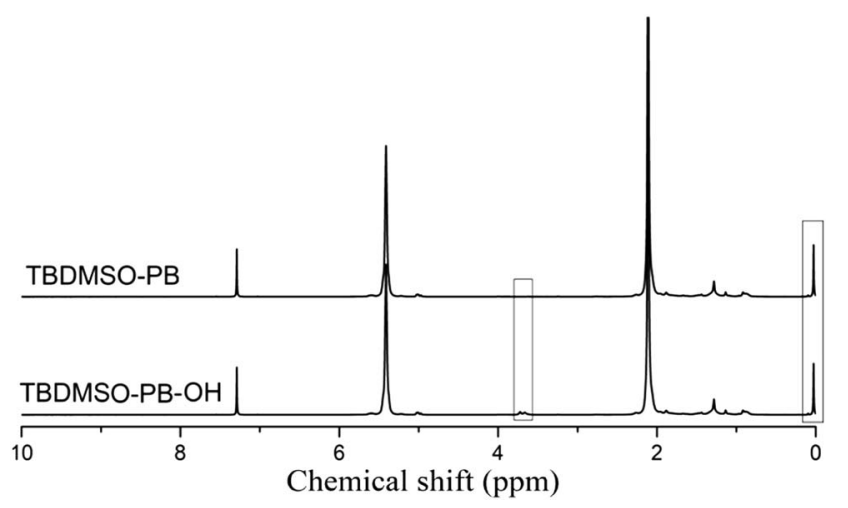

Fig. $3{ }^{1} \mathrm{H}-\mathrm{NMR}$ spectra of TBDMSO-PB and TBDMSO-PB-OH.

difference being $2 \%$. Therefore, we could minimize the "deadend" chain caused by chain termination by controlling the polymerization process.

In addition, we have provided some conditions in Table 4 to analyze the correlation between the monomer/initiator ratio and $M_{\mathrm{n}}$. The results in Table 4 suggest that the $M_{\mathrm{n}}$ reduced when the monomer amount was low. The measured $M_{\mathrm{n}}$ was higher than the expected $M_{\mathrm{n}}$. The reason may be that the three components in the $\mathrm{Li}-\mathrm{Ni}-\mathrm{B}$ system can produce more than one

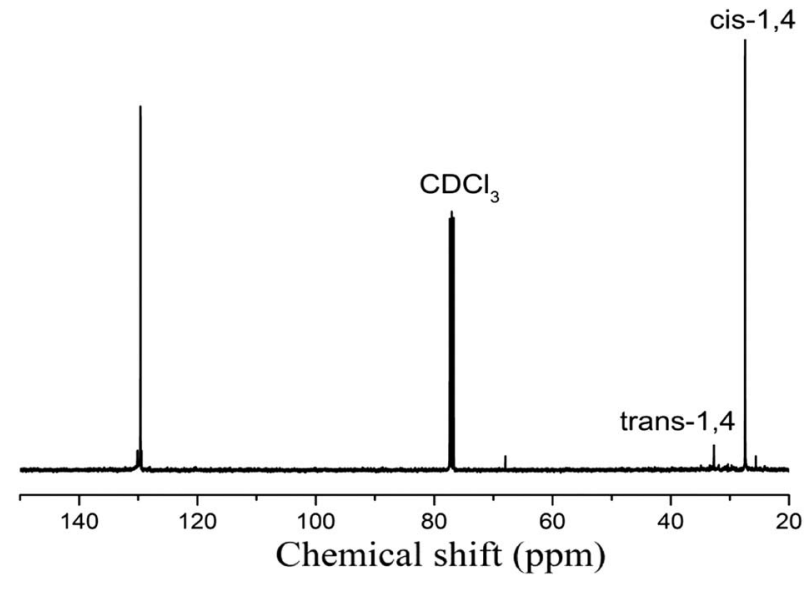

Fig. $4{ }^{13} \mathrm{C}-\mathrm{NMR}$ spectrum of HTPB synthesized by the Li-Ni-B initiator system.

Ni complex, and some of these Ni complexes may have initiating activity, while others may not. Thus, the actual amount of activity centres are lower than the initial amount of $\mathrm{Ni}(\mathrm{naph})_{2}$, which results in higher actual $M_{\mathrm{n}}$ than the expected $M_{\mathrm{n}}$. Besides, the molecular weight and molecular weight distribution of the polymer were measured by gel permeation chromatography (GPC) using DAWN EOS type gel osmotic chromatography-multi-angle laser light scattering (SECMALLS) with $d_{\mathrm{n}} / d_{\mathrm{c}}=0.12$, which can test the absolute $M_{\mathrm{w}}$ of the polymer without a polystyrene standard calibration curve, and calculate the $M_{\mathrm{n}}$ of the polymer by a series of standard methods.

\section{Structural characterization of HTPB synthesized by Li-Ni-B initiating system}

${ }^{1} \mathrm{H}$-NMR (Fig. 1) and ${ }^{13} \mathrm{C}-\mathrm{NMR}$ (Fig. S12 $\dagger$ ) were used to identify the high cis-1,4 contents and presence of hydroxyl terminals in the HTPB sample synthesized by the Li-Ni-B system. The polymerization conditions of the samples in Fig. 1 and $\mathrm{S} 1 \dagger$ were: $\mathrm{Ni}$ amount $=2 \times 10^{-5} \mathrm{~mol}$, Bd (15 wt\%, $n$-hexane) $10 \mathrm{~mL}$, $\mathrm{Li} / \mathrm{B}=1: 2, \mathrm{Li} / \mathrm{Ni}=10: 1,50{ }^{\circ} \mathrm{C}, 4 \mathrm{~h}$. In Fig. 1 , the ${ }^{1} \mathrm{H}-\mathrm{NMR}$ shows $5.4 \mathrm{ppm}$ as chemical shift of the 1,4 structure (cis-1,4 


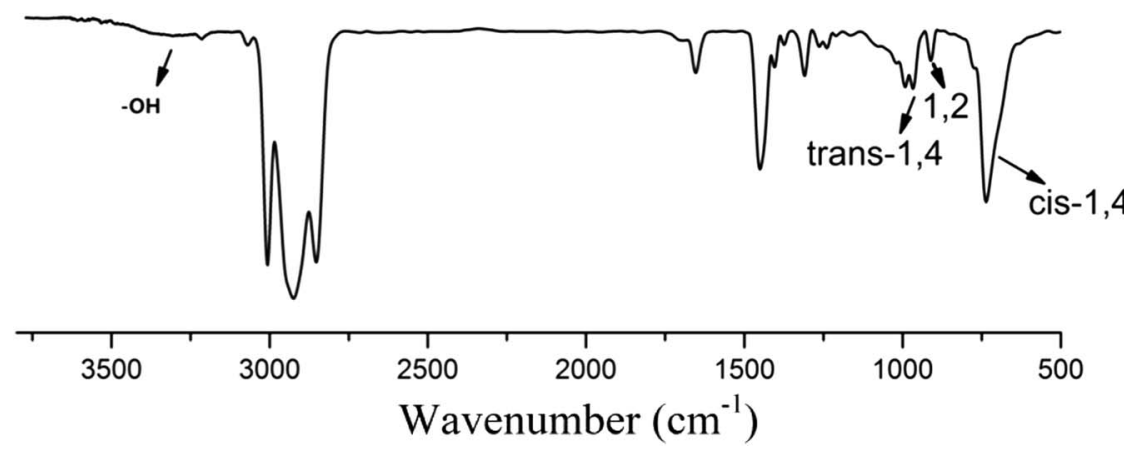

Fig. 5 FT-IR spectrum of HTPB synthesized by the Li-Ni-B initiator system.

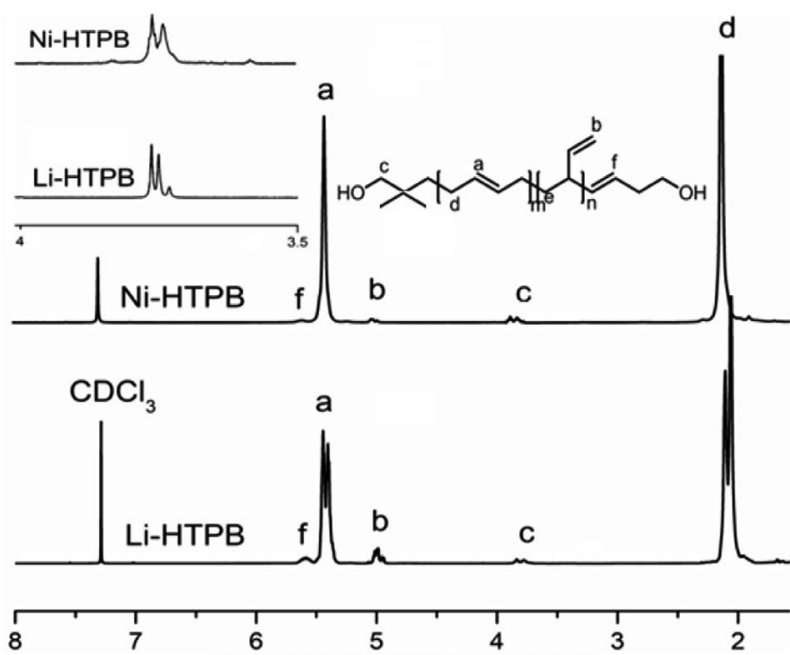

Fig. $6{ }^{1} \mathrm{H}$-NMR spectral comparison between Li-HTPB and Ni-HTPB.
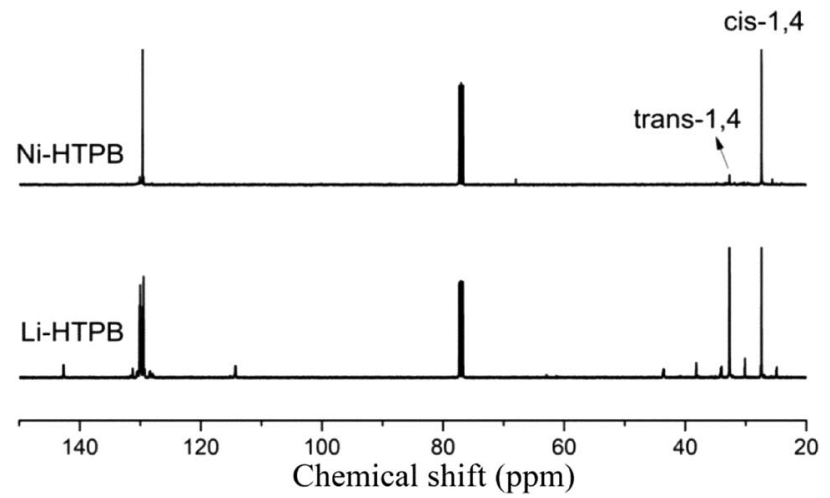

Fig. $7{ }^{13}$ C-NMR spectral comparison between Li-HTPB and Ni-HTPB.

and trans-1,4), whereas $5.0 \mathrm{ppm}$ is attributed to the chemical shift of the 1,2 unit. The integral calculations estimated the content of the 1,4 structures to be $97 \%$ and that of the 1,2 units to be $3 \%$. Moreover, the chemical shift of the $-\mathrm{CH}_{2}-$ groups linked to the hydroxyl groups was observed at $3.8 \mathrm{ppm}$, indicating the presence of hydroxyl terminals in the polymer.
To demonstrate the success of the hydrolysis reaction, ${ }^{1} \mathrm{H}$ NMR spectra (without interior label TMS) of the polymers before and after hydrolysis were studied, and the results are shown in Fig. 2. The polymerization conditions of the two samples in Fig. 2 were: $\mathrm{Ni}$ amount $=2 \times 10^{-5} \mathrm{~mol}$, Bd $(15 \mathrm{wt} \%$, $n$-hexane) $10 \mathrm{~mL}, \mathrm{Li} / \mathrm{B}=1: 2,50{ }^{\circ} \mathrm{C}, 4 \mathrm{~h}$. Among them, the TBDMSO-PB sample was not hydrolyzed, and oxirane was not added in polymerization system. The HO-PB sample was hydrolyzed after polymerization, and oxirane was not added in polymerization system.

Note that ethylene oxide was not added to the system. After hydrolysis, the chemical shift of $\mathrm{Si}-\mathrm{CH}_{3}$ vanished, meaning a thorough hydrolysis of TBDMS. Moreover, TBDMSO-PB did not show a chemical shift in the $-\mathrm{CH}_{2}-\mathrm{OH}$ peak without ethylene oxide, but $-\mathrm{CH}_{2}-\mathrm{OH}$ appeared after hydrolysis, further confirming successful hydrolysis.

To prove the reaction of ethylene oxide with the active end of the polymer, two experiments were performed, and the ${ }^{1} \mathrm{H}-\mathrm{NMR}$ (without the interior label TMS) results are displayed in Fig. 3. The polymerization conditions of the two samples in Fig. 3 were: Ni amount $=2 \times 10^{-5} \mathrm{~mol}$, Bd (15 wt $\%, n$-hexane) $10 \mathrm{~mL}$, $\mathrm{Li} / \mathrm{B}=1: 2,50{ }^{\circ} \mathrm{C}, 4 \mathrm{~h}$. TBDMSO-PB and TBDMSO-PB-OH represent the polymers without and with the addition of ethylene oxide. They were not hydrolyzed after polymerization. TBDMSO-PB showed no chemical shift of the $-\mathrm{CH}_{2}-\mathrm{OH}$ peak, but $-\mathrm{CH}_{2}-\mathrm{OH}$ appeared after the addition of ethylene oxide. Hence, ethylene oxide had reacted with the active end of the polymer to form hydroxyl groups.

To further study the cis-1,4 content in HTPBs synthesized by the Li-Ni-B system, ${ }^{13} \mathrm{C}-\mathrm{NMR}$ was used to calculate the cis-1,4 content since ${ }^{1} \mathrm{H}$-NMR was unable to distinguish the cis-1,4 and trans-1,4 structures. The polymerization conditions used of the sample shown in Fig. 4 were: Ni amount $=2 \times 10^{-5} \mathrm{~mol}$, Bd (15 wt $\%, n$-hexane) $10 \mathrm{~mL}, \mathrm{Li} / \mathrm{B}=1: 2,50{ }^{\circ} \mathrm{C}, 4 \mathrm{~h}$. The characteristic chemical shifts of the cis-1,4 and trans-1,4 structures were recorded at 29 and $32 \mathrm{ppm}$, respectively. After integral calculations, the cis-1,4 content was estimated to be $95 \%$.

The FT-IR spectrum of the HTPB sample with high cis-1,4 content is shown in Fig. 5. The polymerization conditions of sample were: $\mathrm{Ni}$ amount $=2 \times 10^{-5} \mathrm{~mol}, \mathrm{Bd}$ ( $15 \mathrm{wt} \%, n$-hexane) $10 \mathrm{~mL}, \mathrm{Li} / \mathrm{B}=1: 2,50{ }^{\circ} \mathrm{C}, 4 \mathrm{~h}$. The peaks at $724 \mathrm{~cm}^{-1}, 911 \mathrm{~cm}^{-1}$ and $967 \mathrm{~cm}^{-1}$ were the characteristic absorption peaks of the 


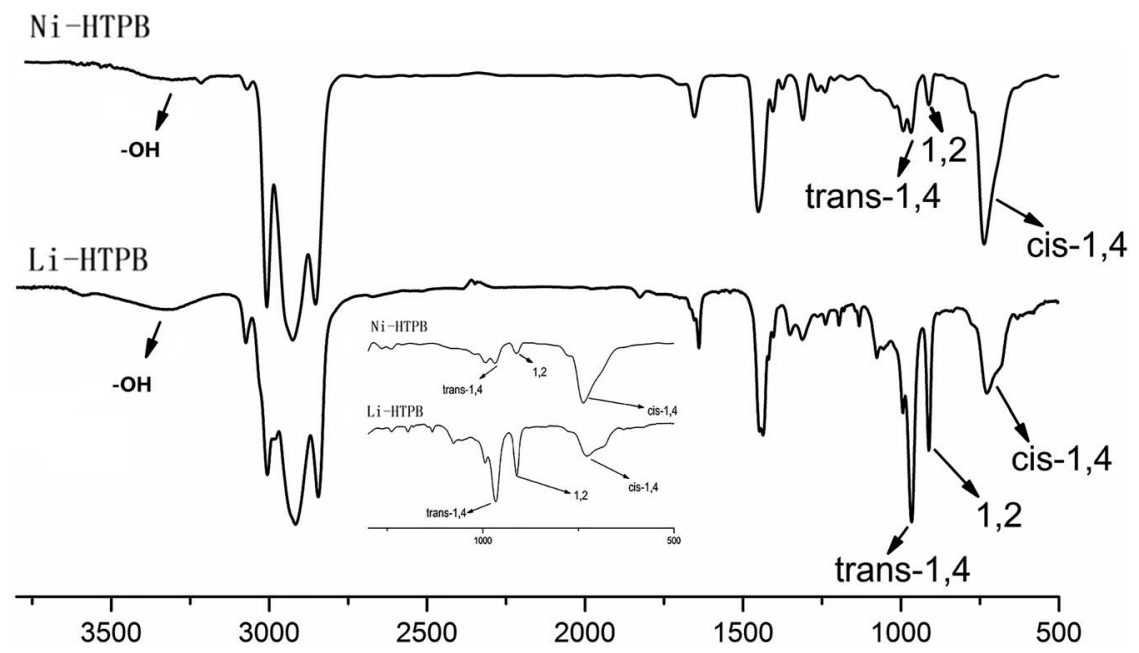

Fig. 8 FT-IR spectral comparison between Li-HTPB and Ni-HTPB.

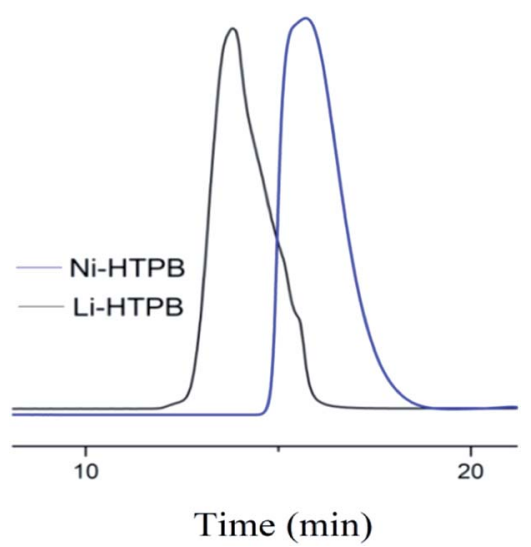

Fig. 9 GPC comparison between Li-HTPB and Ni-HTPB.

cis-1,4, 1,2 unit and trans-1,4 structures, respectively. The contents of these structures in the HTPB sample synthesized by the Li-Ni-B ternary compound were estimated by integral calculations to be $95 \%, 2 \%$ and $\mathrm{F} 3 \%$, respectively. These results were consistent with the ${ }^{13} \mathrm{C}-\mathrm{NMR}$ spectra. The absorption peak at $3500 \mathrm{~cm}^{-1}$ was characteristic of $-\mathrm{OH}$, indicating the presence of hydroxyl terminals in the polymer.

\section{Comparison of the HTPB samples synthesized by Li-Ni-B and anionic polymerization}

Fig. 6 compares the ${ }^{1} \mathrm{H}-\mathrm{NMR}$ of the HTPB samples obtained by the Li-Ni-B system (Ni-HTPB) and anionic polymerization (LiHTPB). The Ni-HTPB polymerization conditions of the samples in Fig. 6-10 were: Ni amount $=2 \times 10^{-5} \mathrm{~mol}$, Bd (15 wt\%, $n$ hexane) $10 \mathrm{ml}, \mathrm{Li} / \mathrm{B}=1: 2,50{ }^{\circ} \mathrm{C}, 4 \mathrm{~h}$. The Li-HTPB polymerization conditions of the samples in Fig. 6-10 were: $\mathrm{Li}$ amount $=2$ $\times 10^{-5} \mathrm{~mol}$, Bd (15 wt $\%, n$-hexane) $10 \mathrm{~mL}, 50{ }^{\circ} \mathrm{C}, 4 \mathrm{~h}$.

The 1,4 content was significantly higher in Ni-HTPB than in Li-HTPB. After integral calculations, the 1,4 content in Ni-HTPB was recorded as 97\%, while that in Li-HTPB was 91\%. Moreover, $3.8 \mathrm{ppm}$ represented the chemical shift of the $-\mathrm{CH}_{2}$ - group linked to $\mathrm{OH}$, indicating the presence of hydroxyl groups in both systems.

${ }^{13} \mathrm{C}-\mathrm{NMR}$ was used to further illustrate the difference in the cis-1,4 content (Fig. 7). The estimated cis-1,4 content in Ni-HTPB by integral calculations was 95\%, while that in Li-HTPB was $43 \%$.

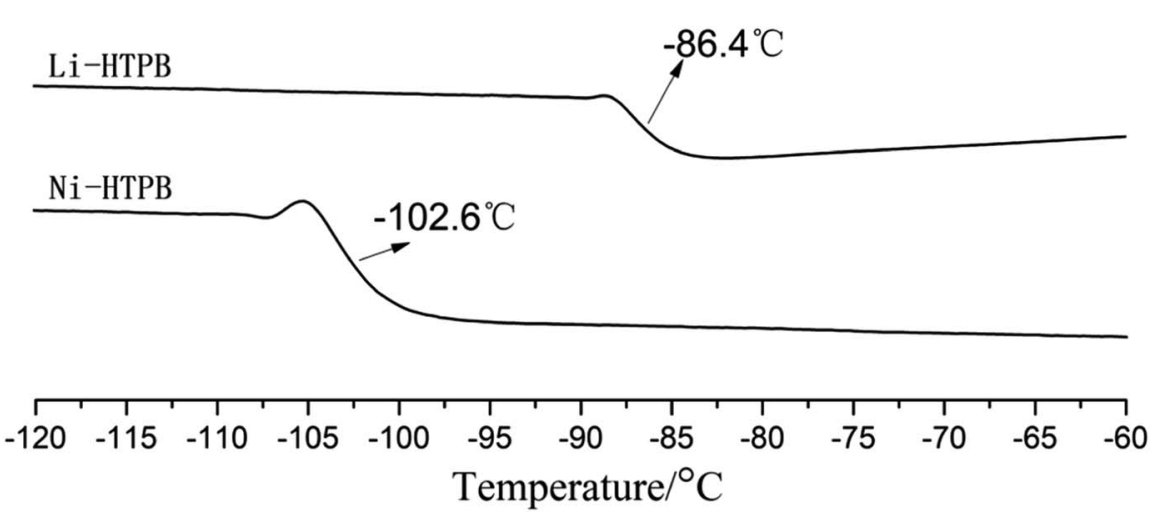

Fig. 10 DSC curves of Ni-HTPB and Li-HTPB. 
Fig. 8 represents the FT-IR profiles of the HTPB samples obtained by the two different polymerization methods. After integral calculations, the cis-1,4 content in Ni-HTPB was determined as $95 \%$, whereas that in Li-HTPB was $43 \%$, consistent with the ${ }^{13} \mathrm{C}-\mathrm{NMR}$ data.

Fig. 9 compares the GPC of the HTPB samples obtained by the two different polymerization methods. The molecular weight distributions of Ni-HTPB and Li-HTPB were 1.2 and 1.1, respectively. This suggested that both systems produced HTPB with narrow size distributions.

Compared with HTPB synthesized by anionic polymerization (Li-HTPB), the most significant feature of HTPB synthesized by the $\mathrm{Li}-\mathrm{Ni}-\mathrm{B}$ system (Ni-HTPB) was its $T_{\mathrm{g}}$. We tested the two HTPB samples by differential thermal scanning (DSC), and the results are shown in Fig. 10. The DSC curves suggested that the $T_{\mathrm{g}}$ of Ni-HTPB was obviously lower than that of Li-HTPB, which meant that the low-temperature mechanical property of $\mathrm{Ni}$ HTPB is better than that of Li-HTPB.

\section{Conclusions}

To obtain HTPB with high cis-1,4 content, a new initiating system comprising of TBDMSODPrLi, nickel naphthenate, boron trifluoride ether ( $\mathrm{Li}-\mathrm{Ni}-\mathrm{B})$ was designed to overcome the defect of the $\mathrm{Ni}-\mathrm{Al}-\mathrm{B}$ system, which could not be directly used to prepare HTPB with high cis-1,4 structure content. The polymerization process indicated that the initiation system was obtained by the reaction of Li with a small amount of Bd solution $(0.5 \mathrm{~mL})$ for $15 \mathrm{~min}$ followed by the addition of $\mathrm{Ni}$ for $15 \mathrm{~min}$. The initiating system showed excellent activity at $\mathrm{Li} / \mathrm{Ni}=10: 1$ and $\mathrm{Li} / \mathrm{B}=1: 2$. The ${ }^{1} \mathrm{H}-\mathrm{NMR}$, FT-IR and ${ }^{13} \mathrm{C}-\mathrm{NMR}$ results estimated the cis-1,4 content in HTPB synthesized by $\mathrm{Li}-\mathrm{Ni}-\mathrm{B}$ to be $95 \%$, which was significantly higher than that in HTPB prepared by anionic polymerization. Although the controllability of the Li-Ni-B system is slightly worse than anionic polymerization, its ability to produce excellent $c i s-1,4$ content is novel and important in the HTPB synthesis field. Moreover, the above-mentioned results show that the PDI and $M_{\mathrm{n}}$ of HTPB synthesized by the Li-Ni-B system can be adjust by controlling the process and obtaining narrow weight distributions. Overall, the novel Li-Ni-B initiation system looks promising as an efficient coordinated anionic polymerization initiation system to prepare HTPB with high cis-1,4 structure content.

\section{Funding}

This work was supported by the scientific research project of the Ministry of Industry and Information Technology of P. R. China (No. JSJL2016140B004).

\section{Conflicts of interest}

The authors declare no conflict of interest.

\section{Acknowledgements}

This work was supported by the Key Laboratory of Macromolecule Science and Technology of Shannxi province of China.

\section{References}

1 R. M. Shankar, T. K. Roy and T. Jana, Terminal functionalized hydroxyl-terminated polybutadiene: An energetic binder for propellant, J. Appl. Polym. Sci., 2009, 114(2), 732-741.

2 Q. q. Sun, Z. Lu, L. Zhang, K. Du and X. Luo, The Synthesis of Hydroxyl-terminated Polyisoprene Telechelic Polymers with High Level of 1,4-Structures, Acta Chim. Sin., 2008, 66, 117-120.

$3 \mathrm{X}$. Min and X. Fan, $\eta^{3}-\pi$-Allyl Acetoxyl Ni Complex, an Efficient Initiator for Synthesis of Hydroxyl-Terminated Polybutadiene with High cis-1,4 Unit Content, Macromol. Chem. Phys., 2018, 219, 1800479.

4 L. T. DeLuca, L. Galfetti, F. Maggi, G. Colombo, L. Merotto, M. Boiocchi, C. Paravan, A. Reina, P. Tadini and L. Fanton, Characterization of HTPB-based solid fuel formulations: Performance, mechanical properties, and pollution, Acta Astronaut., 2013, 92, 150-162.

$5 \mathrm{~W}$. Zhou and J. Cai, Mechanical and dielectric properties of epoxy resin modified using reactive liquid rubber (НTPB), J. Appl. Polym. Sci., 2012, 124, 4346-4351.

6 R. Manjari, V. C. Joseph, L. P. Pandureng, et al., Structureproperty relationship of HTPB-based propellants. I. Effect of hydroxyl value of HTPB resin, J. Appl. Polym. Sci., 1993, 48(2), 271-278.

7 J. Chen, Z. Lu, G. Pan, et al., Synthesis of hydroxyl-terminated polybutadiene possessing high content of 1,4-units via anionic polymerization, Chin. J. Polym. Sci., 2010, 28(5), 715-720.

$8 \mathrm{X}$. Min and X. Fan, Utilization of steric hindrance of alkyl lithium-based initiator to synthesize high 1,4 unitcontaining hydroxyl-terminated polybutadiene, $R$. Soc. Open Sci., 2018, 5, 180156.

9 R. M. Shankar, T. K. Roy and T. Jana, Terminal functionalized hydroxyl-terminated polybutadiene: An energetic binder for propellant, J. Appl. Polym. Sci., 2009, 114(2), 732-741.

10 M. C. Throckmorton and F. S. Farson, An HF-Nickel- $\mathrm{R}_{3} \mathrm{Al}$ Catalyst System for Producing High Cis-1,4-Polybutadiene, Rubber Chem. Technol., 1972, 45(1), 268-277.

11 C. Juan, María del Mar Conejo, Manuel L. Reyes, Kurt Mereiter and Elisa Passaglia, h6-Arene complexes of $\mathrm{Ni}(\mathrm{II})$, efficient catalysts for 1,3-butadiene and styrene polymerization, Chem. Commun., 2003, 78-79.

12 M. A. Hillmyer and S. B. T. Nguyen, Utility of a Ruthenium Metathesis Catalyst for the Preparation of EndFunctionalized Polybutadiene, Macromolecules, 1997, 30, 718-721.

13 D. Gong, B. Wang, C. Bai, et al., Metal dependent control of cis-/ trans-1,4 regioselectivity in 1,3-butadiene polymerization catalyzed by transition metal complexes supported by 2,6-bis[1(iminophenyl)ethyl]pyridine, Polymer, 2009, 50(26), 6259-6264.

14 C. Dixon, E. W. Duck and D. P. Grieve, High cis-1,4 Polybutadiene I The catalyst system nickel Diisopropylsalicylate, boron trifluoride etherate, butyllithium, Eur. Polym. J., 1970, 6, 1359-1370. 